\title{
Simple And Green Synthesis of Calcium Alginate/Hydroxyapatite Hybrid Material Without High Temperature Treatment And Its Flame Retardancy
}

\author{
Qiying Huang \\ Qingdao University \\ Hanjing Xue \\ Qingdao University \\ Ruitao Dong \\ Qingdao University \\ Yun Xue \\ Qingdao University \\ Xiaodong Zhou \\ Qingdao University \\ Zichao Li \\ Qingdao University \\ Qun Li ( $\square$ qunli@qdu.edu.cn ) \\ Qingdao University https://orcid.org/0000-0003-0532-105X
}

\section{Research Article}

Keywords: Hybrid material, Calcium alginate, Hydroxyapatite, Flame retardancy, Mechanism

Posted Date: September 22nd, 2021

DOI: https://doi.org/10.21203/rs.3.rs-875067/v1

License: @) (7) This work is licensed under a Creative Commons Attribution 4.0 International License. Read Full License

Version of Record: A version of this preprint was published at Cellulose on January 30th, 2022. See the published version at https://doi.org/10.1007/s10570-021-04373-w. 


\section{Abstract}

Aiming to improve the thermal stability and flame retardant properties of calcium alginate, calcium alginate

(CaAlg)/hydroxyapatite (HAP) hybrid material was synthesized in situ by the sol-gel method at room temperature. It was found that the HAP particles were generated from nanospheres to urchin-like microspheres, finally to wrinkled sponge microspheres with the two-dimensional nanostructured surface. The results show that the thermal stability and flame retardancy of the hybrid material were significantly improved, and its mechanism was proposed as HAP promoted the decarboxylation of alginate resulting in carbonization of CaAlg/HAP, and it was the function of soild phase before $350{ }^{\circ} \mathrm{C}$, while the synergistic effects of gas phase and solid phase after $350{ }^{\circ} \mathrm{C}$ that led to the high flame retardancy of CaAlg/HAP.

\section{Introduction}

Alginate is a marine biomass polysaccharide, which is composed of $\beta$-D-mannuronic acid (M blocks) and a-L-guluronic acid (G blocks) in an unspecified sequence (He et al. 2021; Kabir et al. 2020). On account of its biodegradability, recyclability, low price and accessibility (Mokhena et al. 2020), alginate has been used in textile (Yu et al. 2020), decorative materials and other fields (Ahmad et al. 2021), however, some applications of alginate are restrained for its limited flammability (Xu et al. 2021). It has been found that sodium alginate (NaAlg, the most common alginate) can form polyanionic electrolytes under neutral and alkaline conditions, therefore, it can cross-link with divalent cations (Liu et al. 2016b; Liu et al. 2015b; Liu et al. 2015c; Liu et al. 2016c) and trivalent cations (Liu et al. 2015a; Liu et al. 2016a) to form a stable "egg-box" structure microstructurally, and a solgel reaction visually (Hu et al. 2021), resulting in better flame retardant property than NaAlg. G block is the main factor for the formation of "egg-box" (Hecht and Srebnik 2016), and M block is related to mechanical properties of alginate (Liu et al. 2020).

In order to expand the application of alginate, researchers have applied CaAlg more frequently which can be prepared by NaAlg and calcium salt as it exhibits better flame retardancy (Yu et al. 2021b), while CaAlg cannot fulfill the ideal thermal stability and flame retardancy, thus people try to prepare other hybrids to solve these defects(Xu et al. 2021). The synergistic effect between natural biomacromolecules and inorganic compounds has been a hot research direction for scientists recently. Compared with the complex and even harmful doping process of organics (Sun et al. 2021b), inorganics doping is simpler and more environmentally friendly (Chen et al. 2017). In our previous works, the flame retardant properties of CaAlg doped with inorganic substances such as calcium borate (Liu et al. 2018), $\mathrm{Cu}_{2} \mathrm{O}$ (Shao et al. 2019), $\mathrm{Ag}_{3} \mathrm{PO}_{4}$ (Zhang et al. 2020), and $\mathrm{AgCl}$ (Zhang et al. 2021) have been studied.

Hydroxyapatite $\left(\mathrm{Ca}_{10}(\mathrm{OH})_{2}\left(\mathrm{PO}_{4}\right)_{6}, \mathrm{HAP}\right)$, as an inorganic phosphate, may be effectively improve the flame retardancy of alginate for it possesses a very high decomposition temperature (above $1000{ }^{\circ} \mathrm{C}$ ) (Yang et al. 2018). Since HAP is a major component of human teeth and bones, its excellent biocompatibility and bioactivity make it a reliable material of synthetic teeth, artificial bones and drug carriers (Pluta et al. 2018; Sokolova et al. 2020). Now different sizes and morphologies of HAP with multiple properties and applications can be prepared by various methods (Sadat-Shojai et al. 2013; Sarker et al. 2015; Sun et al. 2017). Researchers have obtained applicable materials by combining CaAlg and HAP, such as porous HAP/CaAlg composite beads for improving the cycling performance of pectinase (Qi et al. 2020), and ultralong HAP nanowires/CaAlg hybrids with excellent mechanical properties (Jiang et al. 2017), while flame retardancy and mechanism of these hybrids have not been reported yet.

Among the existing synthesis methods of HAP, hydrothermal and sol-gel method are the common ones, while both of them require a high temperature treatment (Costa et al. 2012). For example, the linear HAP prepared by hydrothermal method needed to be treated at $180{ }^{\circ} \mathrm{C}$ for at least $12 \mathrm{~h}$ (Ma et al. 2017), and it must be calcined at above $1000{ }^{\circ} \mathrm{C}$ in the sol-gel method, or else resulted in amorphous HAP crystals (Ruban Kumar and Kalainathan 2010). Other methods are more complex or time consuming (Mohd Pu'ad et al. 2020; Yelten and Yilmaz 2016). However, due to the pyrolysis of CaAlg when heated, it is impossible to prepare the required hybrid materials directly and simply with phosphate by high temperature calcination or hydrothermal method. Furthermore, it would be more consistent with the concept of green chemistry if the high temperature 
treatment was eliminated. Hence, the synthesis of HAP with practical value at room temperature is meaningful, although challenging.

In this direction, the green and simple sol-gel method without a high temperature treatment was implemented to prepare the CaAlg/HAP hybrid material in this study, and the dynamic characteristics of the consumed $\mathrm{Ca}^{2+}$ and the morphology of HAP particles were studied during the in-situ reaction. Furthermore, the thermal stability, flame retardant properties and its pyrolysis mechanism of CaAlg/HAP were explored, aiming to provide a new approach and theoretical basis to prepare alginate hybrids with high flame retardant properties.

\section{Experiment}

Materials

Sodium alginate ( $\mathrm{NaAlg}$, viscosity range 1.05-1.15 Pa.s, $\mathrm{G} / \mathrm{M}=1.83, \mathrm{M}_{\mathrm{W}}=447,823, \mathrm{M}_{N}=375,577$ ) and Eriochome black $\mathrm{T}$ were purchased from Tianjin Guangfu Fine Chemical Research Institute. Disodium hydrogen phosphate dodecahydrate $\left(\mathrm{Na}_{2} \mathrm{HPO}_{4} \cdot 12 \mathrm{H}_{2} \mathrm{O}\right)$, calcium acetate monohydrate $\left[\mathrm{Ca}\left(\mathrm{CH}_{3} \mathrm{COO}\right)_{2}\right.$, shorthand for $\left.\mathrm{CA}\right]$ and Sodium hydroxide $(\mathrm{NaOH})$ were obtained from Shanghai Sinopharm Chemical Reagent Co., Ltd. Ethylenediamine tetraacetic acid disodium salt $\left(\mathrm{C}_{10} \mathrm{H}_{14} \mathrm{~N}_{2} \mathrm{O}_{8} \mathrm{Na}_{2} \cdot 2 \mathrm{H}_{2} \mathrm{O}, 99.0 \%\right)$ was supplied by Tianjin Ruijinte Chemical Reagent Co., Ltd. NaAlg was chemically pure and other chemicals were of analytical grade, and all chemicals were applied without further purification.

Preparations of CaAlg and CaAlg/HAP hybrid material

$\mathrm{Na}_{2} \mathrm{HPO}_{4} \cdot 12 \mathrm{H}_{2} \mathrm{O}$ of $14.1425 \mathrm{~g}$ was dissolved in $470 \mathrm{~mL}$ deionized water, and the $\mathrm{pH}$ was adjusted to 10 with $1 \mathrm{~mol} / \mathrm{L} \mathrm{NaOH}$, and then $15 \mathrm{~g} \mathrm{NaAlg}$ was added to obtain $500 \mathrm{~mL} 3 \%$ treated sol. Then it was placed in $45^{\circ} \mathrm{C}$ water bath for $4 \mathrm{~h}$, stirred per 20 min until NaAlg was dissolved completely, and was cooled for $12 \mathrm{~h}$ to acquire a colorless transparent bubble-free sol. The $\mathrm{pH}$ of $3 \%$ calcium acetate solution was adjusted to $10-11$ by $1 \mathrm{~mol} / \mathrm{L} \mathrm{NaOH}$. The treated sol was poured into a certain rectangular container and soaked in the calcium acetate solution until the shape was fixed for $24 \mathrm{~h}$, and finally, it was washed and dried to a constant weight. The treated sample was labeled as CaAlg/HAP, and all processes were carried out at room temperature (Tr) except for the dissolution of NaAlg.

In order to explore the changes of HAP during its generative process, a series of investigations were carried out on the reaction of $20 \mathrm{~g}$ treated sol in $200 \mathrm{~mL}$ calcium acetate solution with different concentration as time went on.

For comparison, the sample denoted as CaAlg was prepared as the same process with CaAlg/HAP, only excluding the steps related to $\mathrm{Na}_{2} \mathrm{HPO}_{4} \cdot 12 \mathrm{H}_{2} \mathrm{O}$.

Characterization

The morphology of samples was characterized with scanning electron microscopy (SEM, FEI Quanta FEG 250, USA).

The valence states of elements were analyzed by X-ray photoelectron spectroscopy (XPS, Thermo Fisher K-Alpha 250Xi, USA).

Fourier Transform infrared spectroscopy (FT-IR, Thermo Fisher-Nicolet 6700, USA) was recorded in the range of $4000-500$ $\mathrm{cm}^{-1}$.

The samples were continuously scanned at $2 \theta$ with the range of $0 \sim 90^{\circ}$ at $2^{\circ} /$ min by an X-Ray Diffractomer (XRD, Bruker D8 Advance, Germany).

Inductively coupled plasma optical emission spectrometer (ICP, Agilent ICP-OES 730) was employed to quantitatively determine the content of $\mathrm{Ca}^{2+}$ and $\mathrm{Na}^{+}$in samples, in which the samples were treated by aqua regal, hydrofluoric acid and hydrogen peroxide. 
EDTA titration method was applied to determine the content of $\mathrm{Ca}^{2+}$ in calcium acetate solutions treated with different calcifications.

Flame retardant performance test

Thermogravimetric analysis (TGA, NETZS 209F3, Germany) of samples was measured from 30 to $900^{\circ} \mathrm{C}$ with a heating rate of $10^{\circ} \mathrm{C} / \mathrm{min}$ in nitrogen and air respectively.

The samples (size of $150 \times 60 \times 2 \mathrm{~mm}^{3}$ ) were tested in limiting oxygen index meter (LOI, LFY-606B, Shandong, China) according to ASTM D2863-1997.

The samples (size of $130 \times 13 \times 2 \mathrm{~mm}^{3}$ ) were tested by vertical burning tester (LFY-601A, Shandong, China) in vertical burning test, and the response to an open flame of a sample was determined by UL-94 in accordance with ASTM D3801-19a.

In microscale combustion calorimeter (MCC, Govmark, Farmingdale, NY, USA), samples were heated to $750{ }^{\circ} \mathrm{C}$ with $1{ }^{\circ} \mathrm{C} / \mathrm{s}$ in a nitrogen flow of $80 \mathrm{~cm}^{3} / \mathrm{min}$.

Cone calorimeter (CONE, FTT0242, East Grinstead, UK) operated with a heat flux of $50 \mathrm{~kW} / \mathrm{m}^{2}$ and samples in size of $100 \times 100 \times 2 \mathrm{~mm}^{3}$ according to ISO 5660 .

Thermogravimetry coupled with Fourier transform infrared spectroscopy (TG-FTIR) was conducted and samples were heated to $750{ }^{\circ} \mathrm{C}$ at a heating rate of $20^{\circ} \mathrm{C} / \mathrm{min}$ in a $\mathrm{N}_{2}$ atmosphere, with a flow rate of $50 \mathrm{~mL} / \mathrm{min}$ by a simultaneous thermal analyzer (STA8000, PerkinElmer, England) and a Fourier transform infrared spectroscopy (SQ8 rontier, PerkinElmer, England), in the range of 4000 to $450 \mathrm{~cm}^{-1}$ with a resolution of $2 \mathrm{~cm}^{-1}$.

Pyrolysis gas chromatography-mass spectrometry (Py-GC-MS) was performed by a thermal cracker (EGA/PY-3030D, Frontier, Korishan, Japan) and a gas chromatography/mass spectrometry (TRACE 1310-ISQLT, Thermo Fisher Scientific, USA). The pyrolysis temperatures in the furnace were set to $250{ }^{\circ} \mathrm{C}, 450{ }^{\circ} \mathrm{C}$, and $750{ }^{\circ} \mathrm{C}$ respectively. The samples were heated to $280{ }^{\circ} \mathrm{C}$ at a heating rate of $10{ }^{\circ} \mathrm{C} / \mathrm{min}$, kept in injector for $15 \mathrm{~s}$, and then the temperature was rose at $20^{\circ} \mathrm{C} / \mathrm{ms}$.

\section{Results And Discussion}

Analysis of in situ formation of HAP

The levelling effect was considered when investigated the kinetic characteristics of $\mathrm{Ca}^{2+}$, thus $3.0 \mathrm{wt} . \%, 1.0 \mathrm{wt} . \%$ and $0.6 \mathrm{wt} . \%$ of calcium acetate were used to explore the effect of the formation of $\mathrm{HAP}$ on $\mathrm{Ca}^{2+}$ consumption. The relationships of $\mathrm{Ca}^{2+}$ consumption rate $\mathrm{V}_{\mathrm{Ca}^{2+}}$ (Fig. 1a) and its reciprocal $1 / \mathrm{V}_{\mathrm{Ca}^{2+}}$ (Fig. 1b) over time of samples were plotted intuitively, and linear relations were fitted in Fig. $1 \mathrm{~b}$ with $\mathrm{y}$ for $1 / \mathrm{V}_{\mathrm{Ca}^{2+}}$ and $\mathrm{x}$ for time. The fitted lines overlapped in 3.0 wt.\% and 1.0 wt.\% $\mathrm{CA}$, therefore, Fig. $1 \mathrm{~b}$ showed four linear formulas. The difference between formulas $\otimes$ and $\otimes$ indicated the treated sol consumed more $\mathrm{Ca}^{2+}$ with a faster rate in $0.6 \mathrm{wt} . \% \mathrm{CA}$, which was in agreement with expectation that not only the cross-linking reaction between NaAlg and $\mathrm{Ca}^{2+}$, but also the ion exchange reaction among $\mathrm{Ca}^{2+}, \mathrm{PO}_{4}{ }^{3-}$ and $\mathrm{OH}^{-}$to form $\mathrm{HAP}$ occurred. In addition, $0.81 \mathrm{~g} \mathrm{HAP}$ was produced in $0.6 \mathrm{wt}$ \% CA by calculation, and $0.89 \mathrm{~g}$ in $3.0 \mathrm{wt}$ \% CA according to ICP in Table S1. Faster reaction rate and higher yield implied that $3.0 \mathrm{wt}$ \% CA was the best adoption in subsequent experiments.

The in-situ generation of hexagonal HAP was monitored by XRD (Fig. 1c) and SEM (Fig. 1d-i). CaAlg and HAP began to form as soon as calcified, and the crystallinity of HAP might be confirmed after 10 min (Sinulingga et al. 2021). CaAlg exhibited a smooth layered microstructure (Fig. 1d), while the treated sol generated CaAlg and HAP after calcification for 1 min, with a dense arrangement of spherical nanoparticles of a diameter about $2 \mathrm{~nm}$ on the surface of CaAlg (Fig. 1e). Then the nanosheets were grown in the HAP spherical particles in all directions, forming hierarchical microspheres with one-dimensional nanowires and two-dimensional nanosheets, resulting in urchin-like microspheres with average diameters of $3 \mu \mathrm{m}, 4 \mu \mathrm{m}$ and 6 
$\mu \mathrm{m}$, when calcified for $5 \mathrm{~min}, 10 \mathrm{~min}$ and $30 \mathrm{~min}$ (Fig. 1f-h), respectively. However, when calcified for more than 30 min, the HAP microspheres narrowed their size and tended to be wrinkled sponge microspheres with an average diameter of $2 \mu \mathrm{m}$ after 90 min (Fig. 1i), which was consistent with the constant $\mathrm{V}_{\mathrm{Ca}^{2+}}$ after $90 \mathrm{~min}$ in Fig. 1a. According to Ostwald's "rule of stages", this may be in the reason that HAP tended to form unstable and more soluble phases in the early stage of reaction, and would transform into more stable phases in the later stage (Daryan et al. 2020). CaAlg/HAP semi-interpenetrating polymer network may more tightly contact for wrinkled sponge microspheres with a larger superficial area than smooth microspheres, which was beneficial for HAP to adhere to the layered structure of CaAlg (Fong et al. 2017).

Flame retardant properties of CaAlg and CaAlg/HAP

Thermal stability

TGA was conducted under $\mathrm{N}_{2}$ to explore the pyrolysis process without oxidation reaction, and the two samples showed a similar tend with three intense weight loss processes mainly displayed in Fig. 2a-b. The first stage of the weight loss below 200 ${ }^{\circ} \mathrm{C}$ was mostly the removal of free water and bound water in the samples. The first similar weight loss process suggested that the content of water and the combination with water in both samples were alike. The second stage $\left(200-300{ }^{\circ} \mathrm{C}\right)$ and third stage $\left(300-400{ }^{\circ} \mathrm{C}\right)$ were the primary and complex pyrolysis processes, including the breaking of glycosidic bond, dehydration, decarboxylation, decarbonylation, etc.(Zhang et al. 2021). According to Table. S2, CaAlg/HAP proceeded the second stage of pyrolysis at the lower temperature and occurred less weight loss after $200{ }^{\circ} \mathrm{C}$, resulting in its residue of $11.58 \%$, which was more than that of CaAlg in $900{ }^{\circ} \mathrm{C}$. Possibly, HAP promoted the formation of more stable char and less flammable small molecules during the thermal decomposition in $\mathrm{N}_{2}$, granting the CaAlg better flame retardancy.

As shown in Table. S1, HAP accounted for 0.974 wt.\% in CaAlg/HAP, and HAP was assumed no mass change in TGA for it can exist stably below $1000^{\circ} \mathrm{C}$ (György et al. 2019). If HAP had no effect on the thermal decomposition of CaAlg, the weight loss of CaAlg doped HAP calculated by the theoretical formula should be the same as the experimental CaAlg/HAP. Theoretical residue was calculated according to the following formula (Zhang et al. 2019):

\section{$\mathrm{m}_{\mathrm{cal}}(\%)=\mathrm{m}_{\mathrm{CaAlg}}(\%) \times \frac{1}{1+\mathrm{wt}_{\mathrm{HAP}}}+\mathrm{m}_{\mathrm{HAP}}(\%) \times \frac{\mathrm{wt}_{\mathrm{HAP}}}{1+\mathrm{wt}_{\mathrm{HAP}}}$}

where $\mathrm{m}_{\text {cal }}, \mathrm{m}_{\mathrm{CaAlg}}$ and $\mathrm{m}_{\mathrm{HAP}}$ represented the theoretical char of CaAlg/HAP, experimental char of CaAlg, and char of HAP (calculated as $100 \%$ ), respectively, and $\mathrm{wt}_{\mathrm{HAP}}$ was the mass proportion of HAP in CaAlg/HAP. The obtained theoretical TG curve (blue curve in Fig. 2a) was just a little bit above that of CaAlg. It showed that HAP promoted the carbonization of CaAlg during thermal degradation, possibly because of the thermal insulation of HAP (Liu et al. 2018).

The pyrolysis of samples in air was more complex - oxidation reactions occurred between $\mathrm{O}_{2}$ and the products of CaAlg, leading to a further loss of weight (Xu et al. 2019). As seen in Fig. 2, CaAlg before $402{ }^{\circ} \mathrm{C}$ and CaAlg/HAP before $384{ }^{\circ} \mathrm{C}$ in both atmospheres were in consistence, however, subsequently, the oxygen reacted with the combustible gas born from previous stage, causing one more obvious pyrolysis in Fig. 2c-d. As shown in Table. S2, the lower $\mathrm{R}_{\max }$ and more residue of CaAlg/HAP in air indicated that HAP can prevent oxygen from participating in the thermal decomposition of alginate at high temperature, resulting in a markedly better thermal stability of CaAlg/HAP, compared with that of CaAlg.

SEM and XRD of CaAlg and CaAlg/HAP after calcination in air

According to TGA, CaAlg and CaAlg/HAP were calcined in air at $250{ }^{\circ} \mathrm{C}, 450{ }^{\circ} \mathrm{C}$ and $750{ }^{\circ} \mathrm{C}$ for $1 \mathrm{~h}$ to explore the morphology and composition changes of the prepared samples. Figure 3a-c show that the morphology of CaAlg was slightly irregular deformation when heated at $250^{\circ} \mathrm{C}$ and $450{ }^{\circ} \mathrm{C}$, while at $750{ }^{\circ} \mathrm{C}$, a densely arranged residue structure appeared. However, CaAlg/HAP was significantly different from CaAlg. When heated at $250{ }^{\circ} \mathrm{C}$, the diameter of HAP microparticles started narrowing to about $1-2 \mu \mathrm{m}$, and retained the wrinkled sponge appearance, as shown in Fig. $3 \mathrm{~d}$, while it turned to less than 1 $\mu \mathrm{m}$ at $450{ }^{\circ} \mathrm{C}$, there were many nanopores on the compact surface of the residue which can be observed in Fig. 3e. The XRD in 
Fig. $3 \mathrm{~h}$ meant that these nanopores were formed due to the generation and discharge of $\mathrm{CO}_{2}$ from the decomposition of $\mathrm{CaCO}_{3}$. As seen in Fig. $3 \mathrm{f}$, when CaAlg/HAP was heated at $750{ }^{\circ} \mathrm{C}$, the HAP particles continued shrinking to the diameter of 20 $\mathrm{nm}$ and the nanoparticles were closely arranged on the surface of CaAlg, indicating that the compact surface structure prevented the thermal degradation of CaAlg (György et al. 2019).

As observed in Fig. $3 g$, there was no $\mathrm{CaCO}_{3}$ formed in CaAlg until about $450{ }^{\circ} \mathrm{C}$, and a little $\mathrm{CaCO}_{3}$ decomposed into $\mathrm{CO}_{2}$ and $\mathrm{Ca}(\mathrm{OH})_{2}$ at $750{ }^{\circ} \mathrm{C}$. While as seen in Fig. 3h, the generation of $\mathrm{CaCO}_{3}$ began in CaAlg/HAP when heated at $250{ }^{\circ} \mathrm{C}$, and possibly the inner layer of alginate was covered and protected by $\mathrm{CaCO}_{3}$. At $450{ }^{\circ} \mathrm{C}, \mathrm{CaCO}_{3}$ cracked to produce $\mathrm{CaO}$ and $\mathrm{H}_{2} \mathrm{O}$, and when the temperature rose up to $750{ }^{\circ} \mathrm{C}$, the crystallinity of $\mathrm{CaO}$ increased, indicating that more $\mathrm{CaO}$ formed. It showed that HAP can effectively promote the carbonization of CaAlg during combustion, while HAP crystal not only was undecomposed but also a higher crystallinity at higher temperature emerged.

In terms of the above, HAP with ultra-high temperature resistance absorbed heat to form smaller particles that were tightly packed onto the surface of CaAlg. What's more, HAP promoted faster carbonization of $\mathrm{CaAlg}$ and produced $\mathrm{stable} \mathrm{CaCO}_{3}$ at around $250^{\circ} \mathrm{C}$, and $\mathrm{CaO}$ at around $450^{\circ} \mathrm{C}$ or even higher temperature, which prevented further pyrolysis, and thus improved the flame retardant performance of the hybrid material.

Combustion properties

Table 1

Data from LOI, UL-94, CONE, and MCC.

\begin{tabular}{|c|c|c|c|c|c|c|c|c|c|c|}
\hline \multirow[t]{2}{*}{ Samples } & \multirow[t]{2}{*}{ LOI (\%) } & \multirow{2}{*}{$\begin{array}{l}\text { UL- } \\
94\end{array}$} & \multicolumn{4}{|l|}{ CONE } & \multicolumn{4}{|l|}{ MCC } \\
\hline & & & $\begin{array}{l}\text { TTI } \\
\text { (s) }\end{array}$ & $\begin{array}{l}\text { TSR } \\
\left(\mathrm{m}^{2} / \mathrm{m}^{2}\right)\end{array}$ & $\begin{array}{l}\mathrm{EHC} \\
(\mathrm{MJ} / \mathrm{kg})\end{array}$ & Residue(\%) & $\begin{array}{l}\mathrm{PHRR}_{1} \\
(\mathrm{~W} / \mathrm{g})\end{array}$ & $\begin{array}{l}\mathrm{PHRR}_{2} \\
(\mathrm{~W} / \mathrm{g})\end{array}$ & $\begin{array}{l}\text { THR } \\
(\mathrm{kJ} / \mathrm{g})\end{array}$ & Residue(\%) \\
\hline CaAlg & $46.5 \pm 0.5$ & V-0 & $\begin{array}{l}16.0 \pm \\
1.0\end{array}$ & $\begin{array}{l}3.6 \pm \\
0.2\end{array}$ & $\begin{array}{l}26.4 \pm \\
0.1\end{array}$ & $50.7 \pm 0.3$ & $\begin{array}{l}10.7 \pm \\
0.2\end{array}$ & $\begin{array}{l}9.8 \pm \\
1.4\end{array}$ & $\begin{array}{l}0.8 \pm \\
0.1\end{array}$ & $42.8 \pm 0.1$ \\
\hline CaAlg/HAP & $\begin{array}{l}67.0 \pm \\
1.0\end{array}$ & $\mathrm{~V}-0$ & $\begin{array}{l}16.0 \pm \\
1.0\end{array}$ & $\begin{array}{l}1.12 \pm \\
0.3\end{array}$ & $\begin{array}{l}12.3 \pm \\
0.1\end{array}$ & $61.7 \pm 0.2$ & $\begin{array}{l}9.5 \pm \\
0.1\end{array}$ & $\begin{array}{c}3.8 \pm \\
1.4\end{array}$ & $\begin{array}{l}0.6 \pm \\
0.5\end{array}$ & $52.5 \pm 0.4$ \\
\hline
\end{tabular}

As it can be seen from Table 1, the LOI of CaAlg/HAP was $67 \%$, which was $20.5 \%$ higher than that of CaAlg (Liu et al. 2021), and CaAlg/HAP cannot be ignited in the UL-94 test. The EHC of CaAlg/HAP was reduced to half of CaAlg in the CONE test, PHRR and THR in MCC were significantly reduced, and the residue in CONE and MCC of the samples showed the same tendency with TGA, as displayed in Fig. 2. All these results indicated that the doping of HAP was beneficial for the improvement of the thermal stability and flame retardant properties of CaAlg.

Figure 4a shows the variation of the total smoke release (TSR) from the samples during the CONE test over time. The TSR of CaAlg/HAP was remarkably less than that of CaAlg, possibly because the more char the hybrid material produced, the less smoke containing toxic components was released. Importantly, the less smoke release can reduce casualties in fire (Kong et al. 2021; Yu et al. 2021a).

Since most of the oxygen may be consumed in the real fire cases, the pyrolysis of samples under an anaerobic condition can be studied via MCC. MCC simulates heat release throughout the decomposition of samples in nitrogen (Mensah et al. 2018), thus it may correspond with the TGA in $\mathrm{N}_{2}$ theoretically. As seen in Fig. $2 \mathrm{~b}$ and Fig. $4 \mathrm{~b}$, the third weight loss stage in TGA at $300-400^{\circ} \mathrm{C}$ corresponded to the first heat release stage in $\mathrm{MCC}$, while $400-600^{\circ} \mathrm{C}$ was the second heat release stage with little weight change, suggesting that the chemical energy was converted into heat at $300-600{ }^{\circ} \mathrm{C}$. The less weight loss and HRR of CaAlg/HAP implied that the pyrolysis of hybrid was effectively prevented. There were two potential reasons for the decrease of HRR (Liu et al. 2016b). One was that HAP may catalyze the formation of stable char from CaAlg and contributed to a reduction 
of combustible gas release, which was confirmed by the results of TGA (Fig. 2) and XRD (Fig. 3g-h). The other one was that HAP facilitated the formation of non-flammable gases from alginate such as $\mathrm{CO}_{2}$ and water, which would dilute the concentration of flammable products.

\section{TG-FTIR}

In order to investigate whether the improvement of flame retardant properties was related to the synergistic effect of both of the aforementioned reasons, TG-FTIR was conducted to explore the generation of $\mathrm{CO}_{2}$ and $\mathrm{H}_{2} \mathrm{O}$ during the whole pyrolysis process.

The main functional groups containing carbonyl group $\mathrm{C}=0$ at $1795 \mathrm{~cm}^{-1}$, carbon monoxide $\mathrm{CO}$ at $2182 \mathrm{~cm}^{-1}$, carbon dioxide $\mathrm{CO}_{2}$ at $2362 \mathrm{~cm}^{-1},-\mathrm{CH}$ at $2962 \mathrm{~cm}^{-1}$, and $=\mathrm{CH}$ at $3018 \mathrm{~cm}^{-1}$, and $\mathrm{H}_{2} \mathrm{O}$ at $3732 \mathrm{~cm}^{-1}$ from the 3D images of TG-FTIR were selected to explore the pyrolysis of CaAlg (Fig. 5a) and CaAlg/HAP (Fig. 5b). It was found that C = O, $\mathrm{CO}_{\text {and }} \mathrm{CO}_{2}$ showed a similar generation trend, and all of them were produced apparently above $250{ }^{\circ} \mathrm{C}$, indicating that the pyrolysis of glycosidic bonds was started and a variety of complex reactions occured (Fig. $5 \mathrm{c}-\mathrm{e}$ ). What's more, CaAlg/HAP generated more $\mathrm{C}=0, \mathrm{CO}$ and $\mathrm{CO}_{2}$ than CaAlg did, especially over $350{ }^{\circ} \mathrm{C}$, reflecting that the carboxyl groups or similar groups in CaAlg/HAP were more reactive when heated, which activated more decarboxylation and decarbonylation. $\mathrm{The}-\mathrm{CH}$ and $=\mathrm{CH}$ were markedly generated around $450^{\circ} \mathrm{C}$, as shown in Fig. $5 \mathrm{f}-\mathrm{g}$, suggesting that the macromolecular residues from the samples went on a further crack into smaller chains. As seen in Fig. $2 \mathrm{~h}$, the water was formed throughout the pyrolysis process periodically. Not only $-\mathrm{CH}$ and $=$ $\mathrm{CH}$ but also $\mathrm{H}_{2} \mathrm{O}$ were decreased in CaAlg/HAP, implying that its degree of pyrolysis was significantly reduced. The above functional groups of CaAlg/HAP exhibited a similar trend as CaAlg did, however, it produced more $\mathrm{CO}_{2}$ above $350{ }^{\circ} \mathrm{C}$ and the degree of pyrolysis in the later stage was alleviated. Therefore, it can be inferred that, for the carbonization mechanism of CaAlg/HAP, HAP promoted the decarboxylation of alginate, which may because the interface sites between HAP and alginate was conducive to the occurrence of decarboxylation (Fu and Mei 2021). Since HAP was not decomposed to produce phosphoric acid when heated, its flame-retardant mechanism is not similar to most of phosphates that generate phosphoric acid during heating (Sun et al. 2021a).

Collectively, it can be confirmed that the increasing release of $\mathrm{CO}_{2}$ diluted the combustible gas in the CaAlg/HAP combustion system, and turned to an isolation among air, fuel and heat. In general, it was the combination for production of more stable char earlier and generation of more $\mathrm{CO}_{2}$ over $350{ }^{\circ} \mathrm{C}$ together that improved the flame retardancy of the hybrid material. The high flame retardancy of CaAlg/HAP can be mainly attributed to the synergistic effects of gas phase and condensed phase.

\section{Py-GC-MS}

According to the curves in Fig. 6 and the data in Table S3-4, when the temperature rose from room temperature to $250{ }^{\circ} \mathrm{C}$, CaAlg/HAP produced less $\mathrm{CO}_{2}$ than the CaAlg, indicating that alginate was effectively prevent in the early stage of pyrolysis before $250{ }^{\circ} \mathrm{C}$. However, when the temperature rose to $450{ }^{\circ} \mathrm{C}$, CaAlg/HAP generated more $\mathrm{CO}_{2}$ than CaAlg, and as the temperature continued rising to $750{ }^{\circ} \mathrm{C}$, there was a further increase of $\mathrm{CO}_{2}$, which was in line with more generation of $\mathrm{CO}_{2}$ from $350^{\circ} \mathrm{C}$ in Fig. $5 \mathrm{~d}$. The types and amount of pyrolysis products produced by CaAlg/HAP were less than CaAlg. Such as $\mathrm{CaAlg} / \mathrm{HAP}$ produced less acetic acid than CaAlg significantly at $450^{\circ} \mathrm{C}$, and it produced less kinds of products than CaAlg at $750^{\circ} \mathrm{C}$. It was proved that the flame retardant mechanism of CaAlg/HAP was various at different stages of pyrolysis. The function of solid phase was the main flame retardant mechanism from room temperature to $350^{\circ} \mathrm{C}$, while the synergistic effect of the solid phase and the gas phase worked at $350-750^{\circ} \mathrm{C}$.

Flame-retardant mechanism

The speculative pyrolysis mechanism of CaAlg/HAP with no oxygen involved is presented in Scheme 2, which was extrapolated from the pyrolysis products listed in Table S3 (Xu et al. 2021). According to the morphology and XRD patterns of CaAlg/HAP calcined at $250^{\circ} \mathrm{C}, 450^{\circ} \mathrm{C}$, and $750^{\circ} \mathrm{C}$ (Fig. 2), micron-sized HAP particles with low energy were changed into nano-sized with high energy, because of gaining heat. Therefore, during the whole pyrolysis process, part of the heat was 
received by CaAlg/HAP to obtain a compact structure on the surface of CaAlg, which to some extent delayed the thermal decomposition.

As shown in Fig. S3, hydrogen bonds may be formed between HAP and M blocks, which improved the thermal stability of M blocks. The interface site between HAP and alginate activated the decarboxylation of "egg-box" structure related to $\mathrm{G}$ blocks, which resulted in the generation of $\mathrm{CaCO}_{3}, \mathrm{CaO}$ and $\mathrm{CO}_{2}$ to protect alginate when heated. Dehydration and slight decarboxylation occurred in alginate below $250^{\circ} \mathrm{C}$, thus $\mathrm{CO}_{2}$ and $\mathrm{H}_{2} \mathrm{O}$ were the main products. Less $\mathrm{CO}_{2}$ was produced from CaAlg/HAP below $250^{\circ} \mathrm{C}$, indicating that the formation of $\mathrm{CaCO}_{3}$ protected CaAlg and reduced pyrolysis. The glycosidic bonds inside CaAlg can be broken into $\mathrm{M}$ and $\mathrm{G}$ blocks above $250^{\circ} \mathrm{C}$. M blocks was further cracked into butanedione, acetone and acetic acid in CaAlg as a general rule, while these products significantly reduced in CaAlg/HAP, indicating that less pyrolysis occurred in $\mathrm{M}$ blocks. However, although $\mathrm{CO}_{2}$ accounted for $92.65 \%$ and other components were quietly rare at $750{ }^{\circ} \mathrm{C}$, a little bit of pyrolysis products from $\mathrm{G}$ blocks such as acetaldehyde, 2-methylfuran and furfural can be found from CaAlg/HAP. These results suggested that HAP protected $\mathrm{M}$ blocks by forming hydrogen bonds with it, and promoted the partial decomposition of the "egg-box" structure to produce $\mathrm{CaCO}_{3}$ and $\mathrm{CaO}$ to enhance the thickness and strength of the carbon layer as well. Moreover, $\mathrm{CO}_{2}$ from that was to dilute the flammable gas and prevented further decomposition of alginate at high temperature. The combustion process of CaAlg/HAP in air is exhibited in Fig. 7, and more $\mathrm{CO}_{2}$ was produced than in $\mathrm{N}_{2}$ due to the oxidation reactions.

\section{Conclusion}

In this report, CaAlg/HAP hybrid material was in situ synthesized by a green and simple sol-gel method at room temperature. During the reaction, the HAP spherical particles were grown from nanospheres to urchin-like microspheres, and finally to wrinkled sponge microspheres which was favorable as binding with layered CaAlg for their large surface area. CaAlg/HAP presented remarkably better thermal stability and flame retardant properties, in comparison with CaAlg, such as it had more residue (above $12 \%$ ) in TGA at $900{ }^{\circ} \mathrm{C}$, and its LOI reached $67 \%$, while HRR and TSR were significantly decreased. Furthermore, the flame retardant mechanism of CaAlg/HAP was proposed based on the experimental data and reliable theories. The wrinkled sponge microspheres absorbed energy and transformed into nanoparticles after heating, which alleviated pyrolysis of CaAlg for sharing heat from the external environment. The HAP particles with ultra-high temperature resistance covered on the surface of CaAlg, which also hindered the further decomposition of alginate. What's more, the hydrogen bonds formed by the $\mathrm{M}$ blocks and HAP enhanced the stability of the M blocks. The interface sites between HAP and alginate may facilitate the decarboxylation of the "egg-box" structure made up of $\mathrm{G}$ blocks and $\mathrm{Ca}^{2+}$, resulting in the production of $\mathrm{CaCO}_{3}$ early at $250{ }^{\circ} \mathrm{C}$, and the decarboxylation of $\mathrm{CaCO}_{3}$ at higher temperature to produce more $\mathrm{CaO}$ and $\mathrm{CO}_{2}$. In summary, $\mathrm{HAP}$ promoted decarboxylation of alginate causing carbonization of $\mathrm{CaAlg} / \mathrm{HAP}$, and mainly $\mathrm{CaCO}_{3}, \mathrm{HAP}$, and char were generated below 350 ${ }^{\circ} \mathrm{C}$ in the solid phases, while synergistic effects of gas phase $\mathrm{CO}_{2}$ and solid phases $\mathrm{CaO}, \mathrm{HAP}$, and char over $350{ }^{\circ} \mathrm{C}$ that improved thermal stability and flame retardany of CaAlg/HAP by restraining the transfer among oxygen, fuel and heat.

\section{Declarations}

\section{Conflicts of internet}

The authors declared no conflicts of internet.

\section{Acknowledgments}

This work was supported by the National Natural Science Foundation of China (Grant number 51773102) and State Key Laboratory of Bio-Fibers and Eco-Textiles (Qingdao University, Grant number ZKT20).

\section{References}


1. Ahmad A et al. (2021) A Critical Review on the Synthesis of Natural Sodium Alginate Based Composite Materials: An Innovative Biological Polymer for Biomedical Delivery Applications Processes 9 doi:10.3390/pr9010137

2. Chen W, Liu Y, Liu Y, Wang Q (2017) Preparation of alginate flame retardant containing $P$ and Si and its flame retardancy in epoxy resin Journal of Applied Polymer Science 134 doi:10.1002/app.45552

3. Costa DO, Dixon SJ, Rizkalla AS (2012) One- and three-dimensional growth of hydroxyapatite nanowires during sol-gelhydrothermal synthesis ACS Appl Mater Interfaces 4:1490-1499 doi:10.1021/am201735k

4. Daryan SH, Khavandi A, Javadpour J (2020) Surface engineered hollow hydroxyapatite microspheres: Hydrothermal synthesis and growth mechanisms Solid State Sciences 106 doi:10.1016/j.solidstatesciences.2020.106301

5. Fong KD, Wang T, Kim HK, Kumar RV, Smoukov SK (2017) Semi-Interpenetrating Polymer Networks for Enhanced Supercapacitor Electrodes ACS Energy Lett 2:2014-2020 doi:10.1021/acsenergylett.7b00466

6. Fu J, Mei D (2021) A theoretical study of propionic acid decarboxylation over hydroxyapatite supported platinum catalysts Catal Today 365:181-192 doi:10.1016/j.cattod.2020.05.014

7. György S et al. (2019) Effect of the reaction temperature on the morphology of nanosized HAp J Therm Anal Calorim 138:145-151 doi:10.1007/s10973-019-08255-z

8. He H, Wang Y, Yu Z, Liu J, Zhao Y, Ke Y (2021) Ecofriendly flame-retardant composite aerogel derived from polysaccharide: Preparation, flammability, thermal kinetics, and mechanism Carbohydr Polym 269:118291 doi:10.1016/j.carbpol.2021.118291

9. Hecht H, Srebnik S (2016) Structural Characterization of Sodium Alginate and Calcium Alginate Biomacromolecules 17:2160-2167 doi:10.1021/acs.biomac.6b00378

10. Hu C, Lu W, Mata A, Nishinari K, Fang Y (2021) Ions-induced gelation of alginate: Mechanisms and applications Int J Biol Macromol 177:578-588 doi:10.1016/j.jibiomac.2021.02.086

11. Jiang YY, Zhu YJ, Li H, Zhang YG, Shen YQ, Sun TW, Chen F (2017) Preparation and enhanced mechanical properties of hybrid hydrogels comprising ultralong hydroxyapatite nanowires and sodium alginate J Colloid Interface Sci 497:266-275 doi:10.1016/j.jcis.2017.03.032

12. Kabir II, Sorrell CC, Mofarah SS, Yang W, Yuen ACY, Nazir MT, Yeoh GH (2020) Alginate/Polymer-Based Materials for Fire Retardancy: Synthesis, Structure, Properties, and Applications Polymer Reviews 61:357-414 doi:10.1080/15583724.2020.1801726

13. Kong D, Liu J, Zhang Z, Wang S, Lu Z (2021) Preparation of synergistic silicon, phosphorus and nitrogen flame retardant based on cyclosiloxane and its application to cotton fabric Cellulose 28:8115-8128 doi:10.1007/s10570-021-04019-x

14. Liu J, Yu Z, He H, Wang Y, Zhao Y (2021) A novel flame-retardant composite material based on calcium alginate/poly (vinyl alcohol)/graphite hydrogel: thermal kinetics, combustion behavior and thermal insulation performance Cellulose 28:8751-8769 doi:10.1007/s10570-021-04047-7

15. Liu R, Kong B, Chen Y, Liu X, Mi S (2020) Formation of helical alginate microfibers using different G/M ratios of sodium alginate based on microfluidics Sensors and Actuators B: Chemical 304 doi:10.1016/j.snb.2019.127069

16. Liu Y et al. (2015a) Thermal degradation and pyrolysis behavior of aluminum alginate investigated by TG-FTIR-MS and Py-GC-MS Polym Degrad Stabil 118:59-68 doi:10.1016/j.polymdegradstab.2015.04.010

17. Liu Y, Wang J-S, Zhu P, Zhao J-C, Zhang C-J, Guo Y, Cui L (2016a) Thermal degradation properties of biobased iron alginate film Journal of Analytical and Applied Pyrolysis 119:87-96 doi:10.1016/j.jaap.2016.03.014

18. Liu Y, Zhang CJ, Zhao JC, Guo Y, Zhu P, Wang DY (2016b) Bio-based barium alginate film: Preparation, flame retardancy and thermal degradation behavior Carbohydr Polym 139:106-114 doi:10.1016/j.carbpol.2015.12.044

19. Liu Y, Zhao J-C, Zhang C-J, Guo Y, Cui L, Zhu P, Wang D-Y (2015b) Bio-based nickel alginate and copper alginate films with excellent flame retardancy: preparation, flammability and thermal degradation behavior RSC Advances 5:64125-64137 doi:10.1039/c5ra11048c

20. Liu Y, Zhao J-C, Zhang C-J, Guo Y, Zhu P, Wang D-Y (2015c) Effect of manganese and cobalt ions on flame retardancy and thermal degradation of bio-based alginate films J Mater Sci 51:1052-1065 doi:10.1007/s10853-015-9435-9 
21. Liu $Y$ et al. (2016c) Effect of reactive time on flame retardancy and thermal degradation behavior of bio-based zinc alginate film Polym Degrad Stabil 127:20-31 doi:10.1016/j.polymdegradstab.2015.12.024

22. Liu Z, Li Z, Zhao X, Zhang L, Li Q (2018) Highly Efficient Flame Retardant Hybrid Composites Based on Calcium Alginate/Nano-Calcium Borate Polymers (Basel) 10 doi:10.3390/polym10060625

23. Ma B et al. (2017) One-Dimensional Hydroxyapatite Nanostructures with Tunable Length for Efficient Stem Cell Differentiation Regulation ACS Appl Mater Interfaces 9:33717-33727 doi:10.1021/acsami.7b13313

24. Mensah RA, Xu Q, Asante-Okyere S, Jin C, Bentum-Micah G (2018) Correlation analysis of cone calorimetry and microscale combustion calorimetry experiments J Therm Anal Calorim 136:589-599 doi:10.1007/s10973-018-7661-5

25. Mohd Pu'ad NAS, Abdul Haq RH, Mohd Noh H, Abdullah HZ, Idris MI, Lee TC (2020) Synthesis method of hydroxyapatite: A review Materials Today: Proceedings 29:233-239 doi:10.1016/j.matpr.2020.05.536

26. Mokhena TC, Mochane MJ, Mtibe A, John MJ, Sadiku ER, Sefadi JS (2020) Electrospun Alginate Nanofibers Toward Various Applications: A Review Materials (Basel) 13 doi:10.3390/ma13040934

27. Pluta K, Sobczak-Kupiec A, Poltorak O, Malina D, Tyliszczak B (2018) Bioactivity tests of calcium phosphates with variant molar ratios of main components J Biomed Mater Res A 106:1941-1950 doi:10.1002/jbm.a.36386

28. Qi DP, Gao M, Li XY, Lin JL (2020) Immobilization of Pectinase onto Porous Hydroxyapatite/Calcium Alginate Composite Beads for Improved Performance of Recycle Acs Omega 5:20062-20069 doi:10.1021/acsomega.0c01625

29. Ruban Kumar A, Kalainathan S (2010) Sol-gel synthesis of nanostructured hydroxyapatite powder in presence of polyethylene glycol Physica B: Condensed Matter 405:2799-2802 doi:10.1016/j.physb.2010.03.067

30. Sadat-Shojai M, Khorasani M-T, Dinpanah-Khoshdargi E, Jamshidi A (2013) Synthesis methods for nanosized hydroxyapatite with diverse structures Acta Biomater 9:7591-7621 doi:10.1016/j.actbio.2013.04.012

31. Sarker A, Amirian J, Min YK, Lee BT (2015) HAp granules encapsulated oxidized alginate-gelatin-biphasic calcium phosphate hydrogel for bone regeneration Int J Biol Macromol 81:898-911 doi:10.1016/j.jjbiomac.2015.09.029

32. Shao P, Xu P, Zhang L, Xue Y, Zhao X, Li Z, Li Q (2019) Non-Chloride in Situ Preparation of Nano-Cuprous Oxide and Its Effect on Heat Resistance and Combustion Properties of Calcium Alginate Polymers (Basel) 11 doi:10.3390/polym11111760

33. Sinulingga K, Sirait M, Siregar N, Abdullah H (2021) Synthesis and characterizations of natural limestone-derived nanohydroxyapatite (HAp): a comparison study of different metals doped HAps on antibacterial activity RSC Advances 11:15896-15904 doi:10.1039/d1ra00308a

34. Sokolova V, Kostka K, Shalumon KT, Prymak O, Chen JP, Epple M (2020) Synthesis and characterization of PLGA/HAP scaffolds with DNA-functionalised calcium phosphate nanoparticles for bone tissue engineering J Mater Sci Mater Med 31:102 doi:10.1007/s10856-020-06442-1

35. Sun L et al. (2021a) Preparation, characterization and testing of flame retardant cotton cellulose material: flame retardancy, thermal stability and flame-retardant mechanism Cellulose 28:3789-3805 doi:10.1007/s10570-020-03632-6

36. Sun L et al. (2021b) A novel P/N-based flame retardant synthesized by one-step method toward cotton materials and its flame-retardant mechanism Cellulose 28:3249-3264 doi:10.1007/s10570-021-03728-7

37. Sun TW, Zhu YJ, Chen F (2017) Highly Flexible Multifunctional Biopaper Comprising Chitosan Reinforced by Ultralong Hydroxyapatite Nanowires Chemistry 23:3850-3862 doi:10.1002/chem.201605165

38. Xu P, Shao P, Zhang Q, Cheng W, Li Z, Li Q (2019) A Novel Inherently Flame-Retardant Composite Based on Zinc Alginate/Nano-Cu2O Polymers (Basel) 11 doi:10.3390/polym11101575

39. Xu YJ, Qu LY, Liu Y, Zhu P (2021) An overview of alginates as flame-retardant materials: Pyrolysis behaviors, flame retardancy, and applications Carbohydr Polym 260:117827 doi:10.1016/j.carbpol.2021.117827

40. Yang W et al. (2018) Fabrication of Fully Bio-Based Aerogels via Microcrystalline Cellulose and Hydroxyapatite Nanorods with Highly Effective Flame-Retardant Properties ACS Applied Nano Materials 1:1921-1931 doi:10.1021/acsanm.8b00312

41. Yelten A, Yilmaz S (2016) Various Parameters Affecting the Synthesis of the Hydroxyapatite Powders by the Wet Chemical Precipitation Technique Materials Today: Proceedings 3:2869-2876 doi:10.1016/j.matpr.2016.07.006

Page $10 / 17$ 
42. Yu Z, Liu J, He H, Ma S, Yao J (2021a) Flame-retardant PNIPAAm/sodium alginate/polyvinyl alcohol hydrogels used for fire-fighting application: Preparation and characteristic evaluations Carbohydr Polym 255:117485 doi:10.1016/j.carbpol.2020.117485

43. Yu Z, Liu J, Suryawanshi A, He H, Wang Y, Zhao Y (2021b) Thermal insulating and fire-retarding behavior of treated cotton fabrics with a novel high water-retaining hydrogel used in thermal protective clothing Cellulose doi:10.1007/s10570-02103696-y

44. Yu Z, Suryawanshi A, He H, Liu J, Li Y, Lin X, Sun Z (2020) Preparation and characterisation of fire-resistant PNIPAAm/SA/AgNP thermosensitive network hydrogels and laminated cotton fabric used in firefighter protective clothing Cellulose 27:5391-5406 doi:10.1007/s10570-020-03146-1

45. Zhang Q, Zhang X, Cheng W, Li ZC, Li Q (2020) In situ-synthesis of calcium alginate nano-silver phosphate hybrid material with high flame retardant and antibacterial properties Int J Biol Macromol 165:1615-1625 doi:10.1016/j.ijbiomac.2020.10.085

46. Zhang X, Zhang Q, Xue Y, Wang YW, Zhou XD, Li ZC, Li Q (2021) Simple and green synthesis of calcium alginate/AgCl nanocomposites with low-smoke flame-retardant and antimicrobial properties Cellulose doi:10.1007/s10570-021-03825-7

47. Zhang Z, Dong C, Liu J, Kong D, Sun L, Lu Z (2019) Preparation of a synergistic reactive flame retardant based on silicon, phosphorus and nitrogen and its application to cotton fabrics Cellulose 27:1799-1815 doi:10.1007/s10570-019-02900-4

\section{Figures}
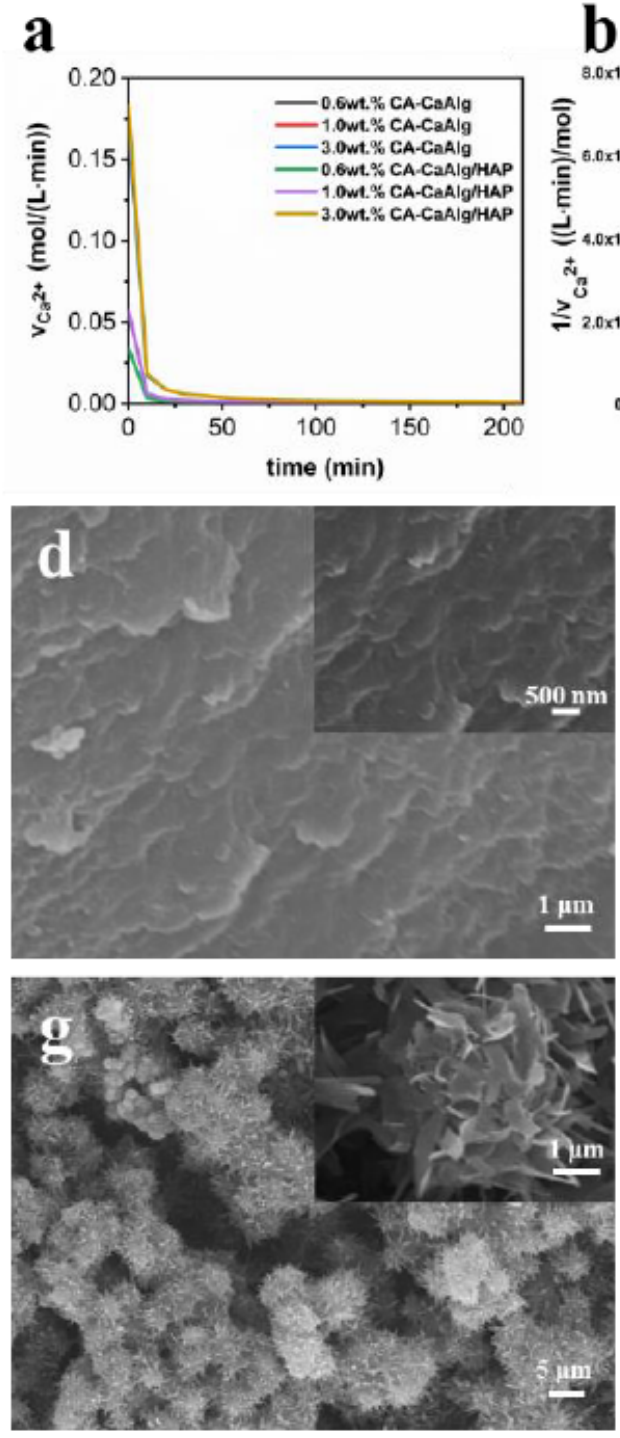
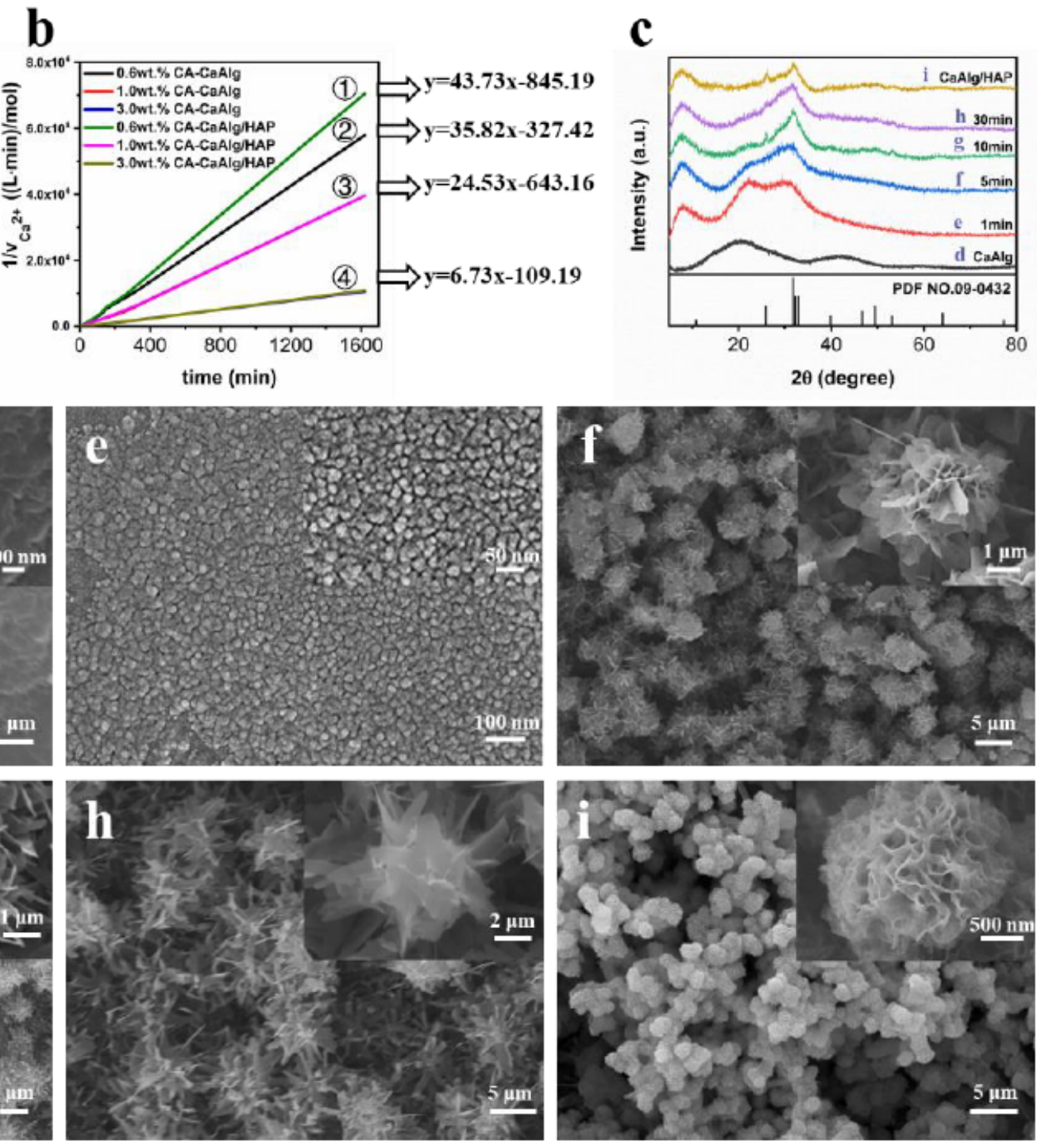
Figure 1

Changes of $\mathrm{Ca} 2+$ consumption rate (a) and their reciprocals (b) in $0.6 \mathrm{wt} . \%, 1.0 \mathrm{wt} . \%$, and $3.0 \mathrm{wt} . \%$ calcium acetate solution (CA) when untreated sol and treated sol calcified into CaAlg and CaAlg/HAP over time, respectively. XRD patterns (c) of CaAlg, and treated sol dipped in $3 \mathrm{wt}$ \% CA for $1 \mathrm{~min}, 5 \mathrm{~min}, 10 \mathrm{~min}, 30 \mathrm{~min}$ and $90 \mathrm{~min}$ (CaAlg/HAP). Morphology microstructures (di) corresponding to the different tested samples shown in Fig. 1(c).
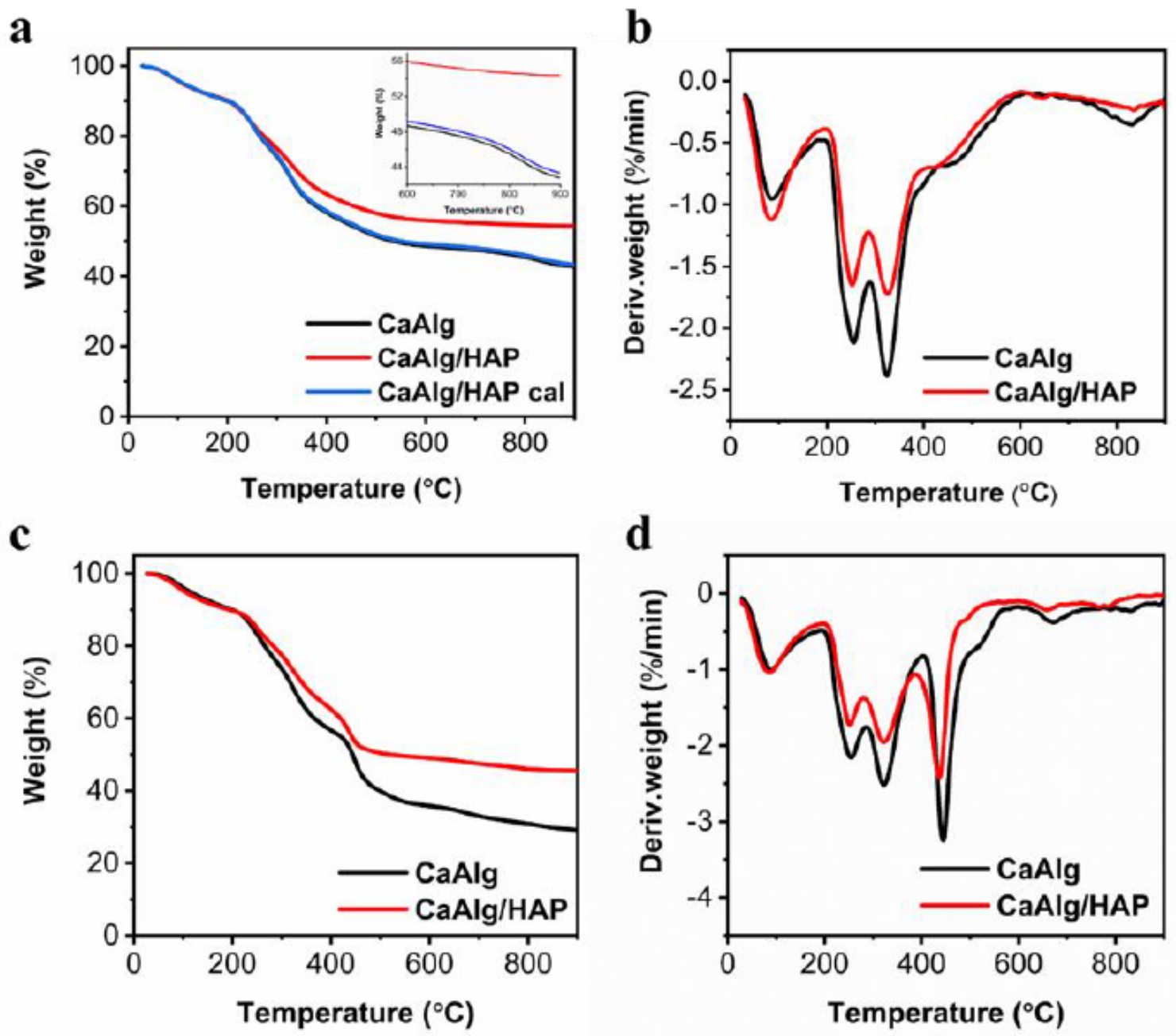

Figure 2

(a) Thermogravimetric analysis (TG) and (b) derivative thermogravimetry (DTG) curves of CaAlg and CaAlg/HAP under nitrogen, (c) TG and (d) DTG curves of CaAlg and CaAlg/HAP under air. 

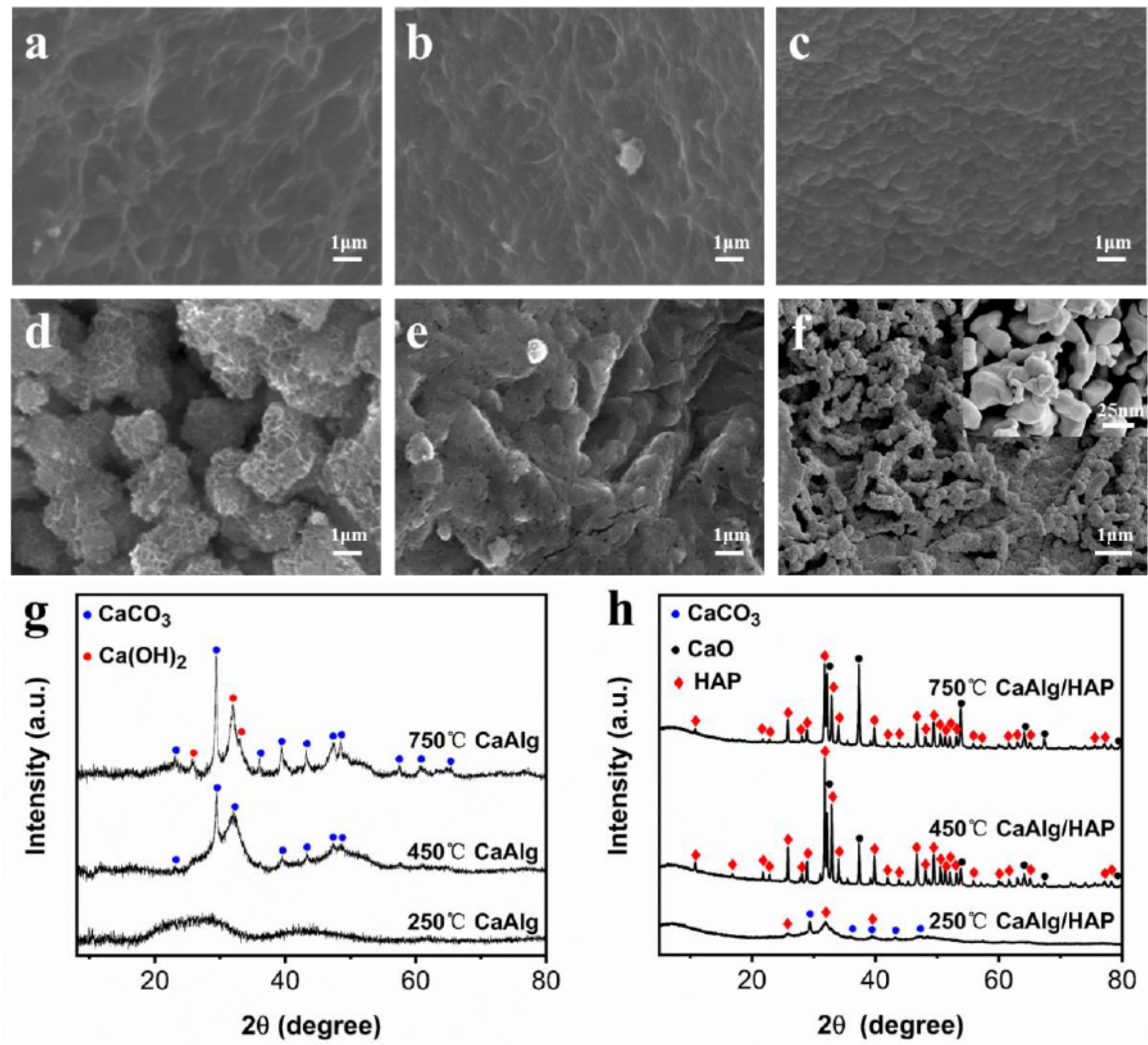

Figure 3

SEM images of (a-c) CaAlg and (d-f) CaAlg/HAP after treated in air at $250^{\circ} \mathrm{C}, 450{ }^{\circ} \mathrm{C}$, and $750{ }^{\circ} \mathrm{C}$ for $1 \mathrm{~h}$, respectively. XRD patterns of (g) CaAlg and (h) CaAlg/HAP after treated in air at $250{ }^{\circ} \mathrm{C}, 450{ }^{\circ} \mathrm{C}$, and $750{ }^{\circ} \mathrm{C}$ for $1 \mathrm{~h}$, respectively. 

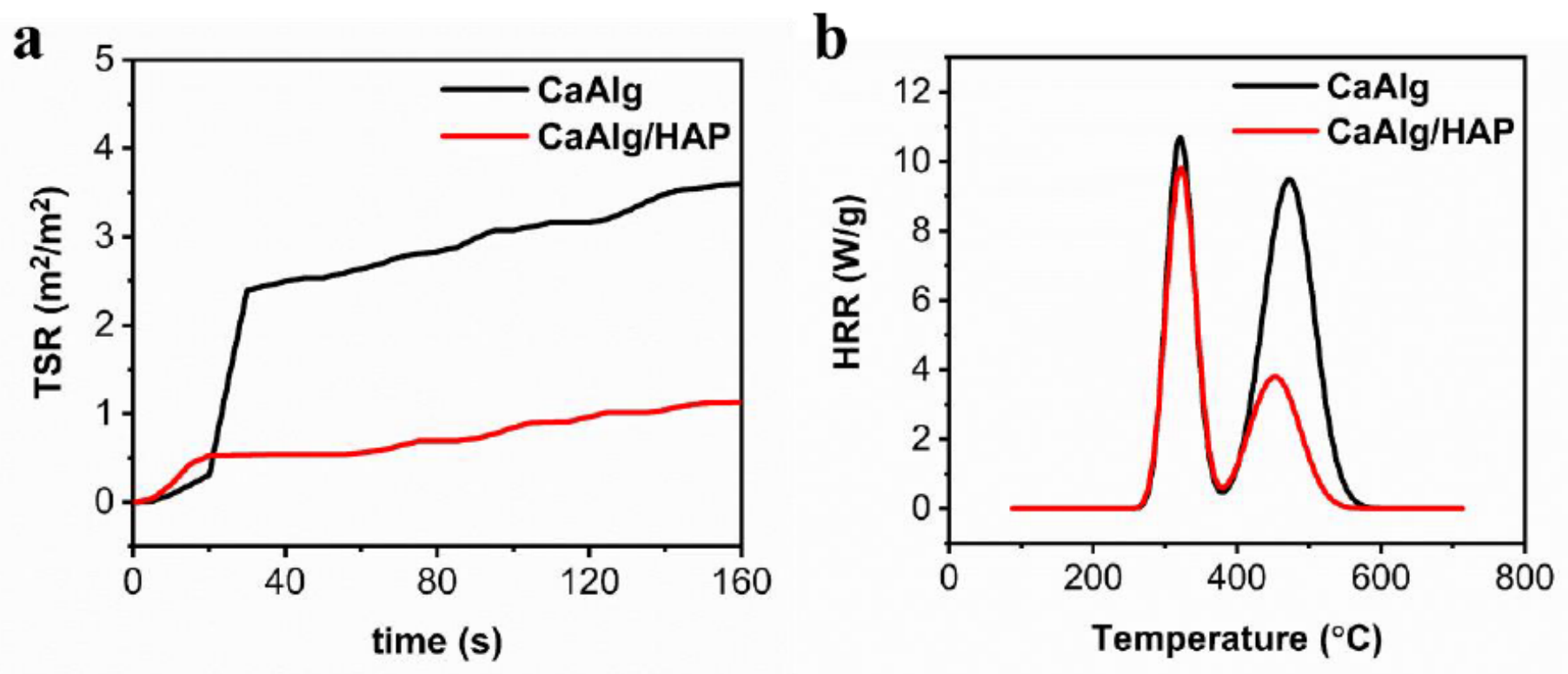

Figure 4

(a) Total smoke release (TSR) over time from CONE and (b) heat release rate (HRR) with temperature from MCC. 
a

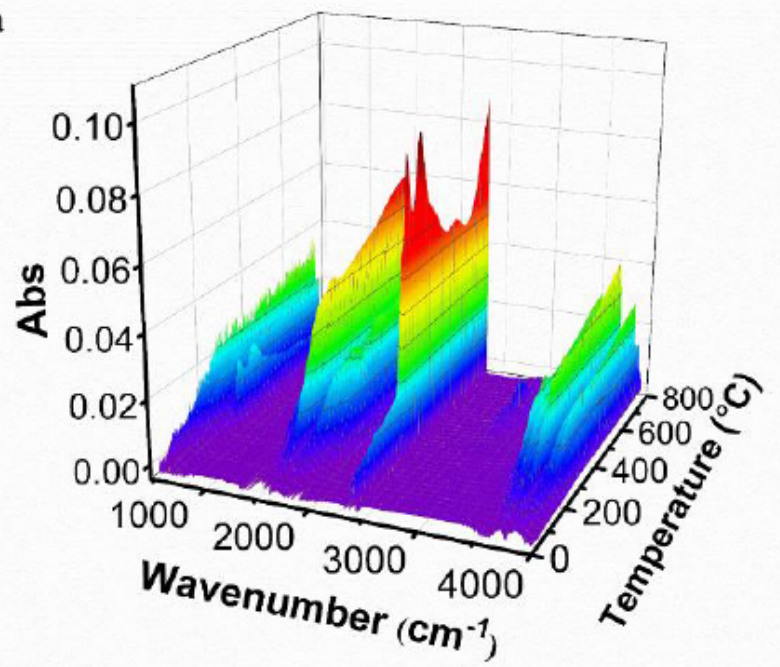

b

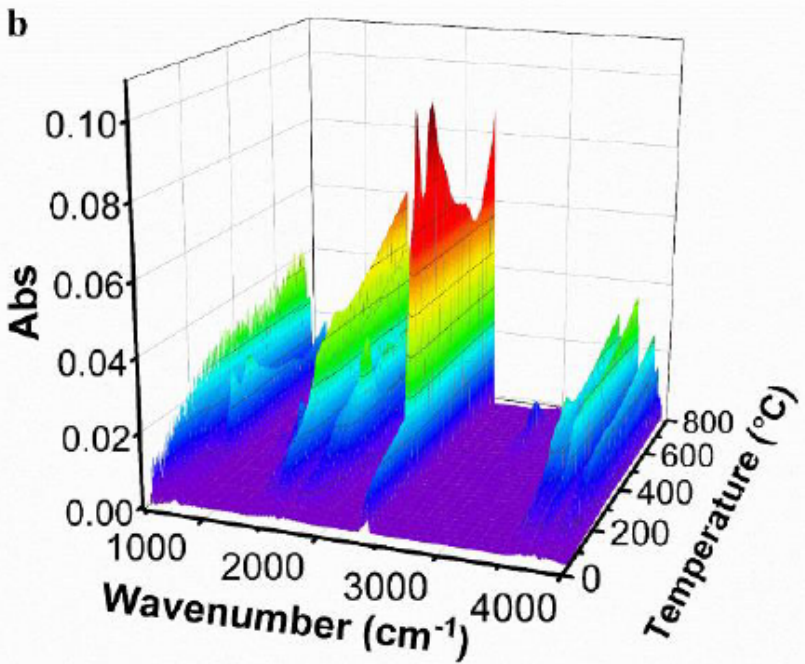

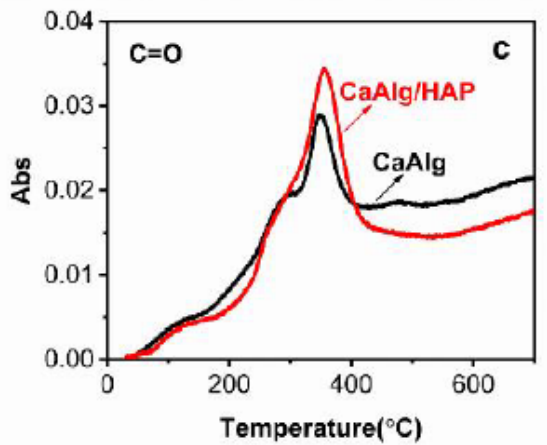
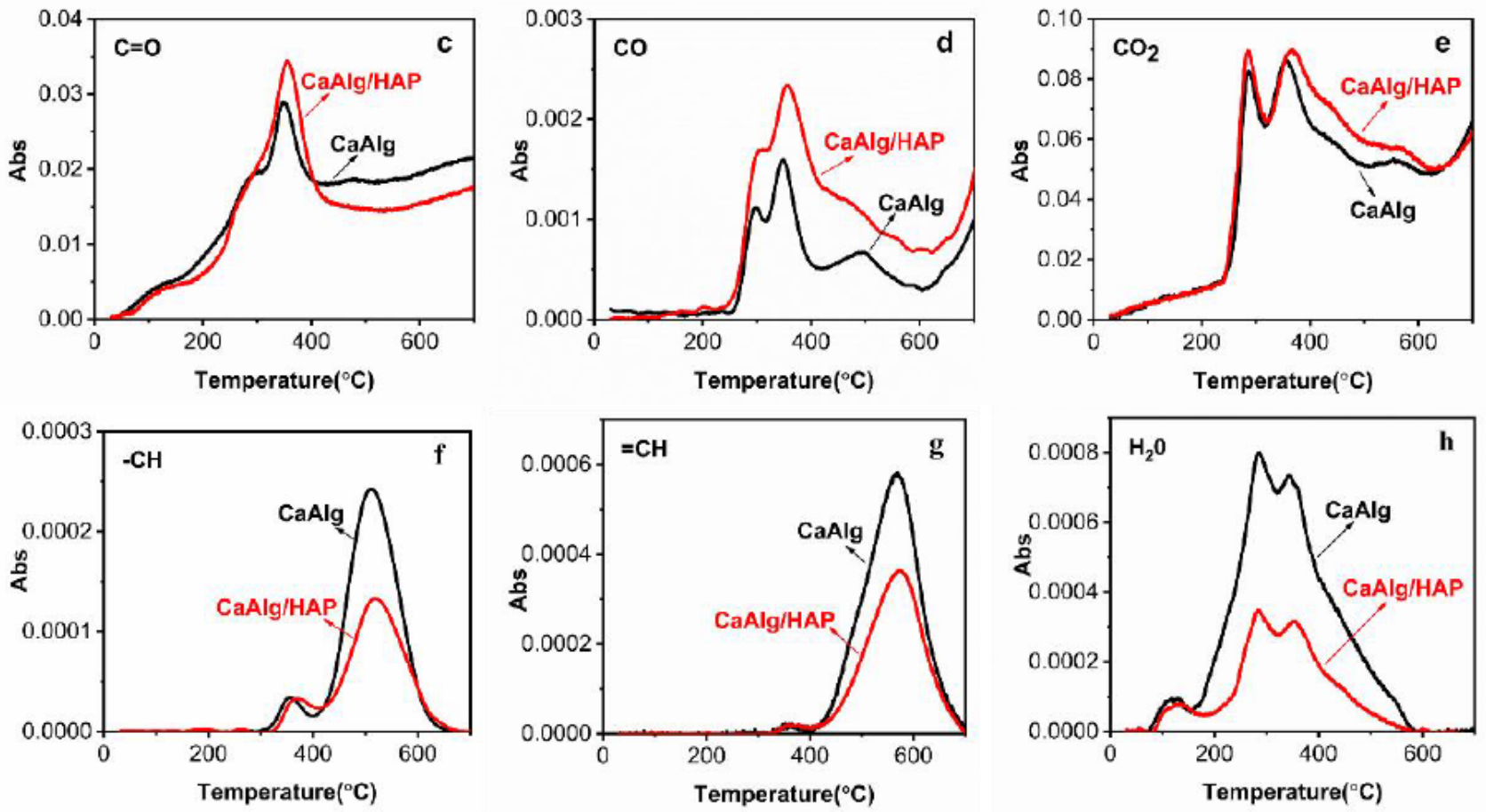

Figure 5

3D images (a-b) and main functional groups as a function of temperature (c-h) of CaAlg and CaAlg/HAP obtained from TGFTIR. 

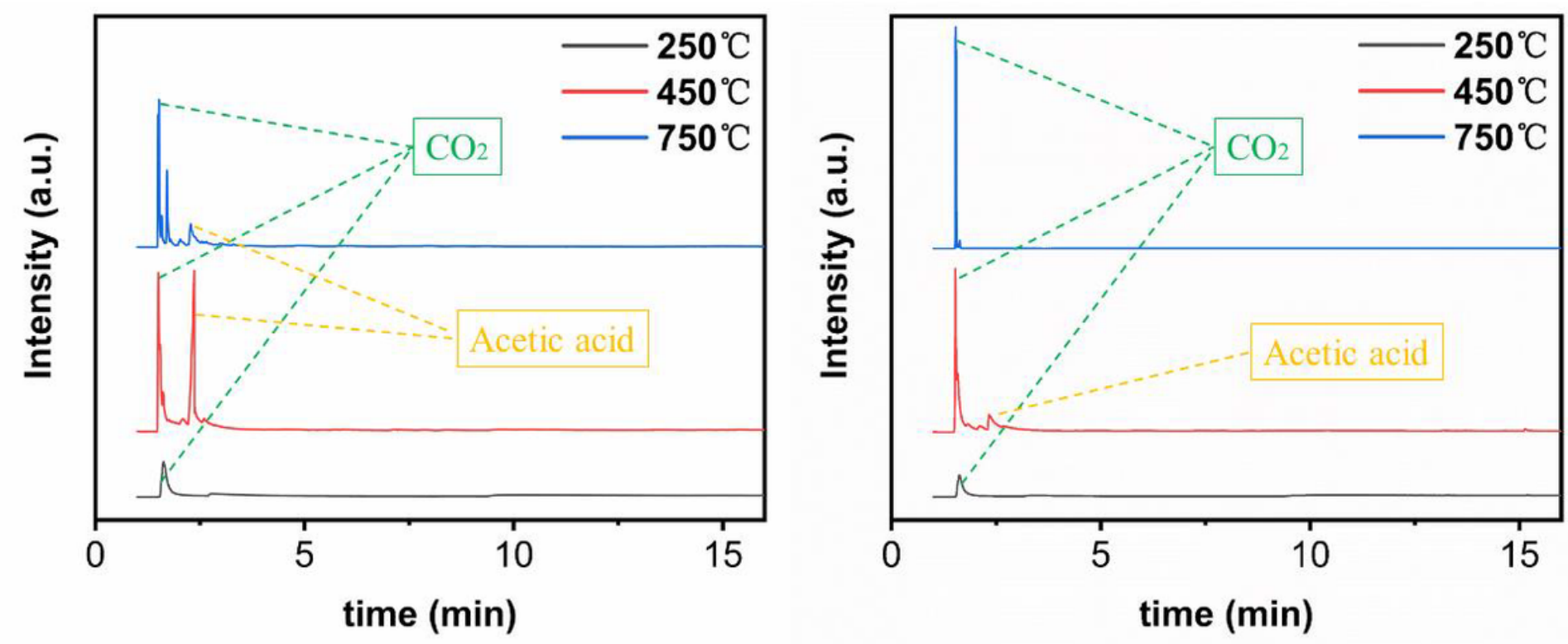

Figure 6

Py-GC-MS detection of gas products formed in pyrolysis of CaAlg (a) and CaAlg/HAP (b) at 250, 450, $750{ }^{\circ} \mathrm{C}$.
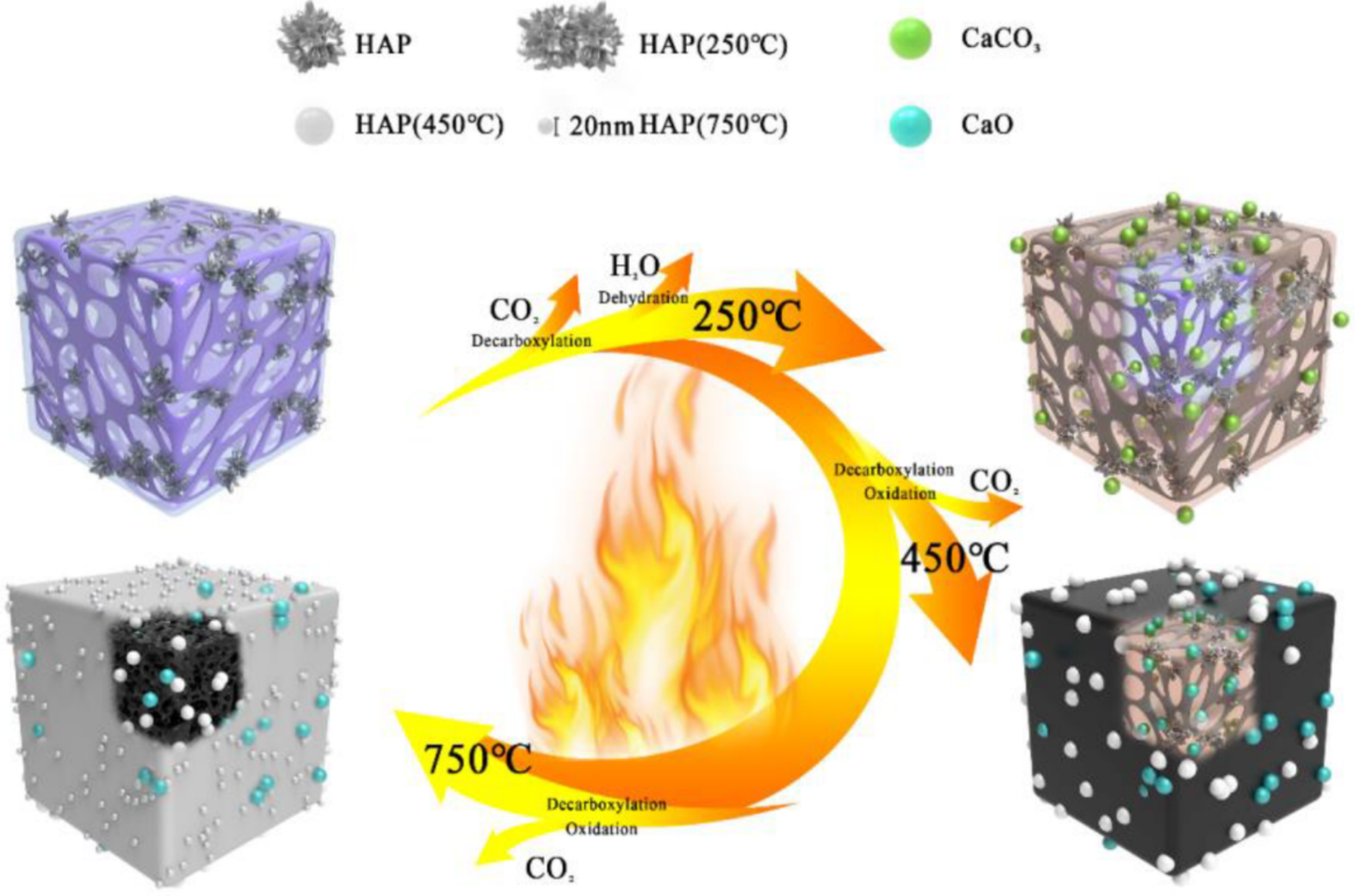

Figure 7 
The combustion process of CaAlg/HAP in air.

\section{Supplementary Files}

This is a list of supplementary files associated with this preprint. Click to download.

- Scheme1.png

- Scheme2.png

- Supplementarylnformation.doc 